\title{
Atlantic salmon Salmo salar instantaneously follow vertical light movements in sea cages
}

\author{
Daniel W. Wright ${ }^{1, *}$, Alexis Glaropoulos ${ }^{2}$, David Solstorm ${ }^{2}$, Lars H. Stien ${ }^{2}$, \\ Frode Oppedal ${ }^{2}$ \\ ${ }^{1}$ Sustainable Aquaculture Laboratory - Temperate and Tropical (SALTT), School of BioSciences, University of Melbourne, \\ Parkville, VIC 3010, Australia \\ ${ }^{2}$ Institute of Marine Research, Matre Research Station, 5984 Matredal, Norway
}

\begin{abstract}
Atlantic salmon in marine farming environments are exposed to potentially detrimental conditions through space and time. For instance, the vertical distribution of parasitic salmon lice larvae shifts in response to changing salinity conditions. We examined whether stock can be moved away from harmful depths using constant-rate vertical movements of lights at night over short periods. Salmon held in research-scale sea cages were exposed to light movements between depths of $0-12 \mathrm{~m}$ and at 5 different speeds $\left(1,2,4,8\right.$ and $\left.16 \mathrm{~m} \mathrm{~min}^{-1}\right)$ on 3 nights. Fish were acclimated to lights fixed at $8 \mathrm{~m}$ depth in a temperature- and salinity-stratified cage environment, partitioning salmon into surface-positioned (47\%) and light-positioned subgroups $(53 \%$ of the population). A high proportion (50-65\%) of the light-positioned group followed lights between upper and lower cage sections when moved up to a critical speed of $4 \mathrm{~m} \mathrm{~min}^{-1}$. However, the surface-positioned group always persisted. Following decreased when lights were moved at higher speeds, equivalent to or faster than fish swimming speeds measured under fixed lighting. Instantaneous vertical light movements at night may effectively move salmon away from fluctuating unsuitable depths (e.g. lice-rich depths), into temporary favourable depths (e.g. surface brackish waters to treat against stenohaline parasites), and throughout cages to avoid crowding in narrow depth ranges.
\end{abstract}

KEY WORDS: Salmo salar $\cdot$ Moving light $\cdot$ Swimming depth $\cdot$ Management $\cdot$ Fish behaviour

\section{INTRODUCTION}

Atlantic salmon Salmo salar distribute variably and unevenly in sea cage environments, selecting preferred depths in response to gradients in environmental and internal drivers (Oppedal et al. 2011). Paradoxically, their position can be at odds with that which optimises their welfare. Harmful depthspecific conditions occur in salmon sea cages (e.g. Dempster et al. 2009), which can fluctuate spatiotemporally. For instance, free-living infective stages of the parasitic salmon louse Lepeophtheirus salmo-

${ }^{*}$ Corresponding author: danielw1@student.unimelb.edu.au nis concentrate at different depths depending on vertical salinity gradients (Jones \& Beamish 2011). Also, salmon periodically aggregating in a narrow depth range at extreme densities (Oppedal et al. 2011) can lower dissolved oxygen levels as they respire (Johansson et al. 2006). These adverse conditions may be mitigated by manipulating salmon depth in sea cages over short time scales.

Artificial light effectively modifies salmon swimming depth in sea cages at night (Juell \& Fosseidengen 2004, Oppedal et al. 2007). Sudden vertical light adjustments reposition salmon (Juell \& Fossei-

() The authors 2015. Open Access under Creative Commons by Attribution Licence. Use, distribution and reproduction are unrestricted. Authors and original publication must be credited. 
dengen 2004), and moving lights in the horizontal plane induce a sustained swimming response in tank-held salmon (Herbert et al. 2011). If salmon also follow constant-rate light movements in vertical trajectories, they could be used by farmers to control salmon depth instantaneously to avoid harmful conditions.

A major concern with using artificial lighting is that other environmental variables affect salmon swimming depth and override light attraction under some circumstances (Oppedal et al. 2011). For instance, light attractiveness fades in temperature-stratified environments when optimal temperatures for salmon thermoregulation $\left(\sim 17^{\circ} \mathrm{C}\right.$; Johansson et al. 2006) occur outside illuminated depths (Oppedal et al. 2007). Attraction also diminishes if lights are of lower intensity (Stien et al. 2014). Therefore, salmon may not be drawn to moving artificial light when overriding motivational factors are present.

To guide stock away from adverse depth-specific conditions, we investigated (1) whether constant-rate vertical light movements induce mass-following of salmon in research-scale sea cages, and (2) what light movement speeds are followed. The experiment was conducted using low-intensity lights in a highly stratified marine environment together reducing the motivational strength of light.

\section{MATERIALS AND METHODS}

Experimental setup. In autumn 2013 at the Institute of Marine Research farm facility at Smørdalen, Masfjorden, Norway $\left(60^{\circ} \mathrm{N}, 5^{\circ} \mathrm{E}\right), 2$ adjacent square research-scale sea cages $\left(12 \times 12 \times 12 \mathrm{~m}, 1728 \mathrm{~m}^{3}\right)$ containing 11000 Atlantic salmon (mean $\pm \mathrm{SE}$; density $=5.74 \mathrm{~kg} \mathrm{~m}^{-3}$, fork length $=39.1 \pm 4.1 \mathrm{~cm}$, mass $=$ $902 \pm 268 \mathrm{~g}$ ) were exposed to light movement treatments of 5 speeds: $1,2,4,8$ and $16 \mathrm{~m} \mathrm{~min}^{-1}$ repeated over 3 consecutive nights (11-12, 12-13 and 13-14 November 2013) (see Fig. 1). These were equivalent to fish swimming speeds of $0.04,0.09,0.17,0.34$, and 0.68 body lengths (BL) $\mathrm{s}^{-1}$ based on mean fish size.

Prior to the trial, fish were adapted to a single lowintensity LED lamp (custom-made lamps, AKVA Group ASA) centrally positioned at $8 \mathrm{~m}$ depth in both cages for 2 mo. Lamp colours were 375-425 nm and total irradiance was adjusted to achieve $0.1 \mu \mathrm{E}$ at $1 \mathrm{~m}$ distance from the light source (see details in Stien et al. 2014). Fish were fed a commercial diet (9 mm, Optiline + pellets, Skretting) using farm practices to satiation, though hunger status on experimental nights was unknown.
On an experimental night, light movement treatments were conducted simultaneously in both cages and in random order (see Fig. 1). Lights remained fixed at $8 \mathrm{~m}$ depth for $15 \mathrm{~min}$ before and after each movement (see Fig. 1). Light vertical movement was provided by hauling lights using an automatic motorised winch (Belitronics HF 5000, Lunde, Sweden) between the surface and cage bottom (starting from a fixed position at $8 \mathrm{~m}$ depth, then down to $12 \mathrm{~m}$, up to $0 \mathrm{~m}$ and back down to $8 \mathrm{~m}$ ) for 3 cycles. Treatments were performed between 19:30 and 00:30 h (local time) after a mean $( \pm \mathrm{SE})$ sunset time of 16:12 h $\pm 1 \mathrm{~min}$ and during a waxing gibbous moon phase.

Fish and light depths. Fish depth was quantified using an echo-integration system (Lindem Data AcquisitionOslo, Norway) cabled to upward facing transducers $\left(42^{\circ}\right.$ beam, $50 \mathrm{KHz}, 0.001 \mathrm{~s}$ pulse, $1 \mathrm{~s}$ echo listening, $6 \mathrm{~s}$ pulse interval) $7 \mathrm{~m}$ below each cage (Bjordal et al. 1993). Echo intensity was captured at $0.07 \mathrm{~m}$ depth intervals between 0.25 and $12 \mathrm{~m}$ and later converted to relative echo intensity as a measure of fish percentages per depth. Light depth was monitored in time-stamped video recordings from underwater cameras $\left(360^{\circ}\right.$ pan/tilt Orbit Subsea camera) secured to the same winch as lights. The number of echo sounder data-points was standardized across treatment replicates by randomly selecting how many data-points were recorded during the fastest light speed treatment (16 $\mathrm{m} \mathrm{min}^{-1}, 52$ data-points).

Fish swimming speed. Swimming speeds of salmon were measured before and after each treatment via underwater cameras. The video system only recorded from one camera at a time, so the recording was swapped between cameras in random order so both cages were viewed before and after treatments. For each period, swim speeds of 15 fish in both north and south directions (1080 measurements in total) were calculated in body lengths (BL) $\mathrm{s}^{-1}$ from the time required for a fish's snout until tail to pass a vertical reference line (Dempster et al. 2009).

Environmental variables. Water temperature, salinity, and dissolved oxygen were measured via a CTD (SD204, SAIV AS) profiling between 0 and $12 \mathrm{~m}$ at $0.6 \mathrm{~m} \mathrm{~min}^{-1}$ on a Belitronics winch. Mean values at $0.5 \mathrm{~m}$ depth intervals were calculated for each experimental night.

Statistical analysis. Differences in mean fish percentages in the upper $6 \mathrm{~m}$ of cages between light depths at $3 \mathrm{~m}$ increments were examined by one-way ANOVA for each light movement treatment. This measure of fish distribution captured changes in the proportion of fish in surface (above $6 \mathrm{~m}$ depth) and light-associated subgroups that were present. Signif- 
icant ANOVA results were followed by Tukey posthoc comparisons to determine statistical groupings. Residual plots and Levene's tests assessed normality and homogeneity of variance, respectively, and data were transformed where appropriate. Levels of significance are $\mathrm{p}<0.05$ and values are presented as mean $\pm \mathrm{SE}$.

\section{RESULTS}

Cage environments were stratified, with a cooler and less saline surface layer, and constant conditions below $6 \mathrm{~m}$ depth. Temperatures and salinities were slightly higher on Night $1\left(9-13^{\circ} \mathrm{C}\right.$ and $19-32 \mathrm{ppt}$, respectively) compared to Night $2\left(8-13^{\circ} \mathrm{C}\right.$ and $12-$ $32 \mathrm{ppt})$ and $3\left(8-13^{\circ} \mathrm{C}\right.$ and $\left.12-31 \mathrm{ppt}\right)$, due to rainfall after the first night. Dissolved oxygen remained $>70 \%$ saturation and was elevated in surface waters (72-90\% saturation).

When lights were fixed at $8 \mathrm{~m}$, fish displayed a bimodal vertical distribution, with a surface-positioned subgroup in the upper $6 \mathrm{~m}$ of cages (mean $\pm \mathrm{SE}$ : $46.9 \pm 0.5 \%)$, and another around the light source in the bottom $6 \mathrm{~m}$ (mean \pm SE: $53.1 \pm 0.5 \%$ ) (Fig. 1). In these instances, fish at lights swam in school formations at a mean speed of $0.36 \pm 0.01 \mathrm{BL} \mathrm{s}^{-1}$.

Light movements generally caused the lightpositioned subgroup to follow the light, while the surface-positioned subgroup persisted, and the 2 groups merged when the light entered surface waters (Fig. 1). Shifts in the percentage of fish between the upper and lower cage sections were detected as lights moved between depths at $1-4 \mathrm{~m} \mathrm{~min}^{-1}\left(F_{3,100}=\right.$ 18.17-36.17, $\mathrm{p}<0.0001)$, but not at the higher speeds $\left(8 \mathrm{~m} \mathrm{~min}^{-1}: F_{3,100}=0.75, \mathrm{p}=0.524 ; 16 \mathrm{~m} \mathrm{~min}^{-1}: F_{3,100}=\right.$ 1.57, $\mathrm{p}=0.202$ ) (Fig. 2). At these lower speeds of $1-4 \mathrm{~m}$ $\mathrm{min}^{-1}$, lights moving through the bottom $3 \mathrm{~m}$ of cages $(9-12 \mathrm{~m})$ resulted in $47.5-48.6 \%$ of fish positioning in the upper $6 \mathrm{~m}$ (Fig. 2), and this shifted to $75.1-82.9 \%$ in the upper $6 \mathrm{~m}$ when lights entered the top $3 \mathrm{~m}$ of cages. The magnitude of this shift increased with decreasing light movement speeds, with 34.4, 29.2, 26.7, 7.1 and $1.2 \%$ of the population moving between upper and lower cage sections at 1, 2, 4, 8 and $16 \mathrm{~m}$ $\mathrm{min}^{-1}$, respectively (Fig. 2). From slowest to fastest movement speeds, the light-followers represented $64.7,55.0,50.3,13.4$ and $2.3 \%$ of the light-associated subgroup that was present under fixed lighting.

\section{DISCUSSION}

We demonstrate that Atlantic salmon Salmo salar in sea cages follow constant-rate vertical light movements at speeds up to $4 \mathrm{~m} \mathrm{~min}^{-1}$. However, in this study a surface subgroup was not attracted by either deep-stationary or moving lights, indicating the pres-
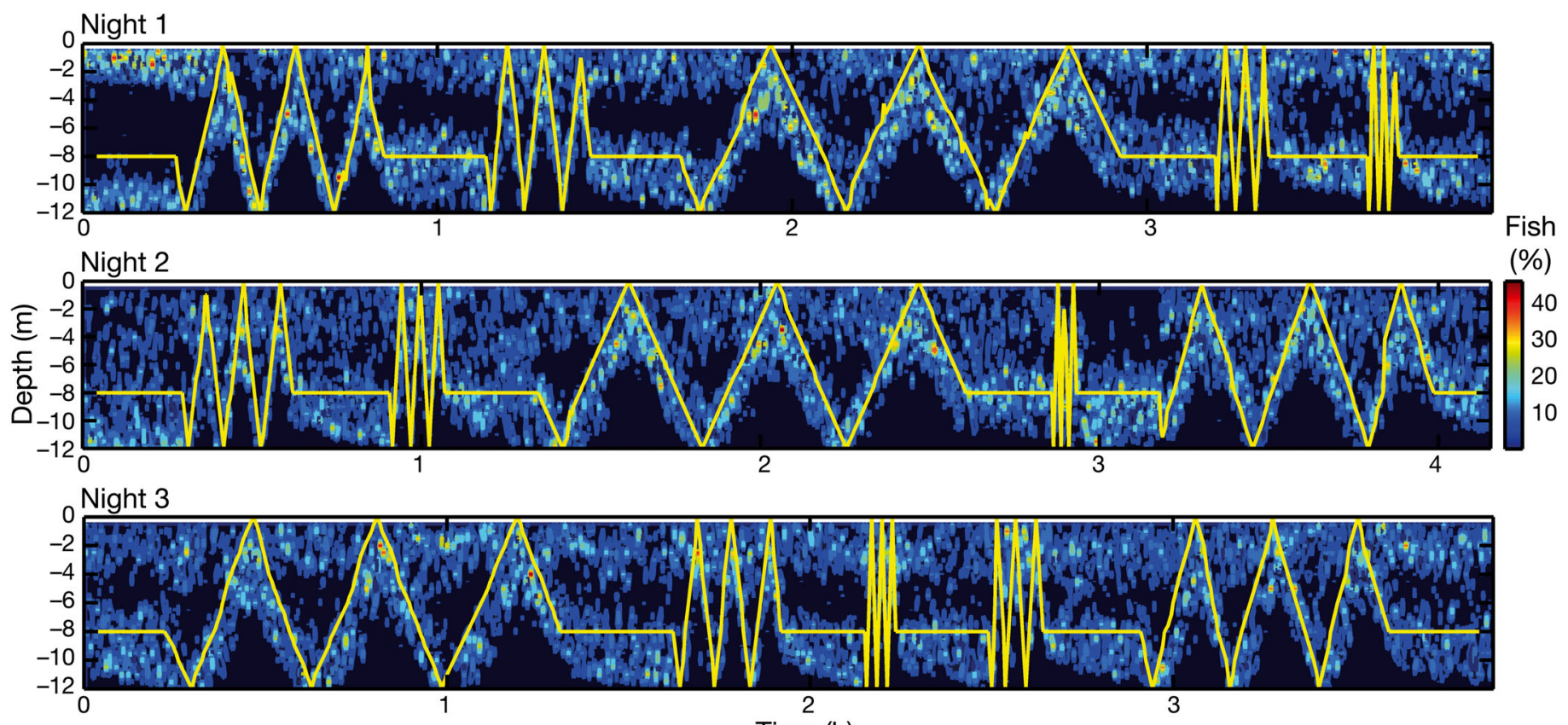

Time (h)

Fig. 1. Depth distribution (colour-coded percentages of fish at $0.5 \mathrm{~m}$ depth increments using data from a single cage) of Atlantic salmon Salmo salar during the 3-night study where fixed submerged lights positioned at $8 \mathrm{~m}$ were moved at a constant rate between $0-12 \mathrm{~m}$ for 3 cycles at 5 different speeds (yellow line indicates light depth) 


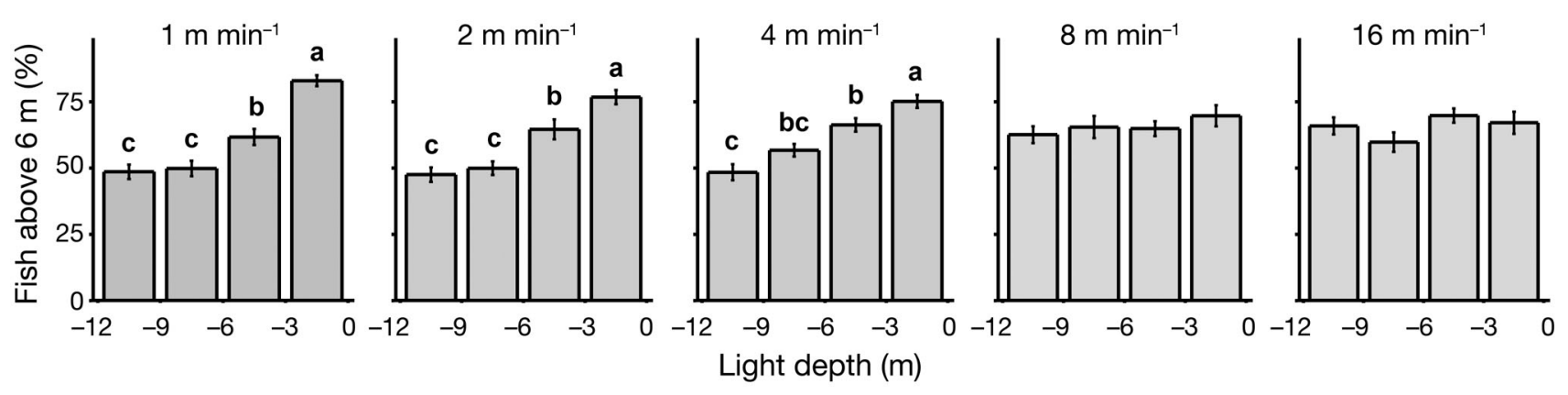

Fig. 2. Mean percentages of Atlantic salmon Salmo salar in the upper $6 \mathrm{~m}$ of cages when lights were within $3 \mathrm{~m}$ depth increments during movements at 1, 2, 4, 8 and $16 \mathrm{~m} \mathrm{~min}^{-1}$. Letters indicate significantly $(\mathrm{p}<0.05)$ different groups from post-hoc (Tukey HSD) comparisons following significant ANOVA results

ence of other overriding motivating factors. Shortterm guidance of fish with lights throughout cage depths has wide-ranging potential applications in salmon farm management.

This is the first report of salmon in sea cages following constant-rate vertical light movements. Juell \& Fosseidengen (2004) found similar salmon depth adjustments when lights were abruptly switched between 5 cage depths over $48 \mathrm{~h}$. The decision to follow lights is likely to preserve visual acuity for schooling behaviour, which requires vision and lateral line senses (Partridge \& Pitcher 1980). Fish may be evolutionarily driven to school to reduce energy expenditure, increase hunting potential, lower predation, and improve tracking of favourable conditions (Handegard et al. 2012, Berdahl et al. 2013, Hemelrijk et al. 2014). The fact that salmon eyes respond slowly to changes in light levels (Guthrie \& Muntz 1993) from daylight to darkness, may also account for the attractiveness of artificial night lighting and the following of moving light sources.

Salmon were not guided by the fastest vertical light movements (8 and $16 \mathrm{~m} \mathrm{~min}^{-1}$ equal to 0.34 , and $0.68 \mathrm{BL} \mathrm{s}^{-1}$ of experimental fish, respectively) which matched or out-paced swimming speeds measured at fixed lighting $\left(0.36 \mathrm{BL} \mathrm{s}^{-1}\right)$. Atlantic salmon are capable of critical swimming speeds up to $3.0 \mathrm{BL} \mathrm{s}^{-1}$ in flow tanks (Lijalad \& Powell 2009); however, fast speeds may not be used by fish groups attempting to occupy moving environmental conditions (patches) they prefer. Berdahl et al. (2013) found fish groups seek out preferred patches by swimming faster as conditions worsen and navigating toward slower swimmers. Reduced swim speeds in optimal spaces also shortens inter-individual distances and increases densities (Berdahl et al. 2013). Moving lights too quickly may not attract large salmon groups because faster individuals tend not to gather followers and are spaced further apart.
A surface-positioned subgroup was not affected by light movements, suggesting the lack of pre-existing motivational strength for artificial light is not changed by these movements. In this study, weakened light attraction may have been attributable to overriding internal factors such as hunger, which motivated fish to reside at the surface (e.g. Frenzl et al. 2014), or environmental conditions. Temperature is known to override light attraction in Atlantic salmon (Oppedal et al. 2007), but it may not have been the driver for the behaviour of the surface-positioned subgroup in this study as warmer depths optimising salmon thermoregulation (Johansson et al. 2006) were in the lower cage sections. It is possible that the surface fish were infected by salmon lice $\left(0.85\right.$ lice fish $^{-1}$ detected before the start of our study) and selected shallow lowsalinity areas to self-treat against these freshwatersusceptible parasites (Gjelland et al. 2014). The surface fish were also potentially excluded from restricted lit areas under low-intensity lighting (Stien et al. 2014) and exhibiting shallow swimming, typical of salmon in cages during the night under natural light (Oppedal et al. 2011). Further research is needed to further define lighting arrangements and movement types that gather more followers. For example, moving commercial anti-maturation lamps $(8-100 \mu \mathrm{E}$, Stien et al. 2014) rather than low-intensity lights $(0.1 \mu \mathrm{E})$ may considerably strengthen following.

\section{CONCLUSION}

Instantaneously moving salmon to new depths with underwater artificial light at night has diverse commercial applications. For best results, our study suggests moving lights at $\leq 4 \mathrm{~m} \mathrm{~min}^{-1}$ and in the absence of overriding factors. Potential applications include steering salmon away from the depth of salmon lice infective stages (cf. Frenzl et al. 2014), which varies 
depending on salinity depth profiles (Jones \& Beamish 2011). Using lights to attract salmon into temporary areas of low salinity (e.g. 12 ppt surface waters in this study) may also cause the removal of attached lice and other ecto-parasites sensitive to low salinities (Bricknell et al. 2006, Parsons et al. 2001). Additionally, moving salmon constantly throughout cage depths may prevent extreme schooling densities in narrow depth ranges (Oppedal et al. 2011), which can cause hypoxic conditions (Johansson et al. 2006). Manipulating salmon swimming behaviour with vertical light movements could therefore improve parasite control, fish welfare and production for the salmon aquaculture industry.

Acknowledgements. Thanks to Jan-Erik Fosseidengen for echo sounder operation, Tone Vågseth for technical support, and Jan Olav Fosse, Stian Morken and Kristian Dahle for research farm upkeep during the study. The experiment was conducted under the authority of the Norwegian ethics committee towards research involving animals, and within the Norwegian Research Council funded Centre for research based innovation in aquaculture (CREATE) with support from industrial partners.

\section{LITERATURE CITED}

Berdahl A, Torney CJ, Ioannou CC, Faria JJ, Couzin ID (2013) Emergent sensing of complex environments by mobile animals. Science 339:574-576

Bjordal A, Juell JE, Lindem T, Ferno A (1993) Hydroacoustic monitoring and feeding control in cage rearing of Atlantic salmon (Salmo salar L.). In: Reinertsen H, Dahle LA, Jørgensen L, Tvinnereim K (eds) Fish farming technology. Balkema, Trondheim, p 203-208

Bricknell IR, Dalesman SJ, O'Shea B, Pert CC, Mordue Luntz AJ (2006) Effect of environmental salinity on sea lice Lepeophtheirus salmonis settlement success. Dis Aquat Org 71:201-212

> Dempster T, Korsøen Ø, Folkedal O, Juell JE, Oppedal F (2009) Submergence of Atlantic salmon (Salmo salar L.) in commercial scale sea-cages: a potential short-term solution to poor surface conditions. Aquaculture 288:254-263

Frenzl B, Stien LH, Cockerill D, Oppedal F and others (2014) Manipulation of farmed Atlantic salmon swimming behaviour through the adjustment of lighting and feeding regimes as a tool for salmon lice control. Aquaculture 424-425:183-188

Editorial responsibility: Chris Noble, Tromsø, Norway
Gjelland KØ, Serra-Llinares RM, Hedger RD, ArechavalaLopez P and others (2014) Effects of salmon lice infection on the behaviour of sea trout in the marine phase. Aquacult Environ Interact 5:221-233

Guthrie DM, Muntz WRA (1993) Role of vision in fish behaviour. In: Pitcher TJ (ed) Behaviour of teleost fishes, 2nd edn. Chapman \& Hall, London, p 89-128

Handegard NO, Boswell KM, Ioannou CC, Leblanc SP, Tjostheim DB, Couzin ID (2012) The dynamics of coordinated group hunting and collective information transfer among schooling prey. Curr Biol 22:1213-1217

> Hemelrijk CK, Reid DAP, Hildenbrandt $\mathrm{H}$, Padding JT (2014) The increased efficiency of fish swimming in a school. Fish Fish. doi:10.1111/faf.12072

$>$ Herbert NA, Kadri S, Huntingford FA (2011) A moving light stimulus elicits a sustained swimming response in farmed Atlantic salmon, Salmo salar L. Fish Physiol Biochem 37:317-325

Johansson D, Ruohonen K, Kiessling A, Oppedal F, Stiansen JE, Kelly M, Juell JE (2006) Effect of environmental factors on swimming depth preferences of Atlantic salmon (Salmo salar L.) and temporal and spatial variations in oxygen levels in sea cages at a fjord site. Aquaculture 254:594-605

Jones S, Beamish R (2011) Salmon lice: an integrated approach to understanding parasite abundance and distribution. Wiley-Blackwell, Oxford

> Juell JE, Fosseidengen JE (2004) Use of artificial light to control swimming depth and fish density of Atlantic salmon (Salmo salar) in production cages. Aquaculture 233:269-282

> Lijalad M, Powell MD (2009) Effects of lower jaw deformity on swimming performance and recovery from exhaustive exercise in triploid and diploid Atlantic salmon Salmo salar L. Aquaculture 290:145-154

> Oppedal F, Juell JE, Johansson D (2007) Thermo- and photo-regulatory swimming behaviour of caged Atlantic salmon: implications for photoperiod management and fish welfare. Aquaculture 265:70-81

> Oppedal F, Dempster T, Stien LH (2011) Environmental drivers of Atlantic salmon behaviour in sea-cages: a review. Aquaculture 311:1-18

$>$ Parsons H, Nowak B, Fisk D, Powell M (2001) Effectiveness of commercial freshwater bathing as a treatment against amoebic gill disease in Atlantic salmon. Aquaculture 195:205-210

> Partridge BL, Pitcher TJ (1980) The sensory basis of fish schools: relative roles of lateral line and vision. J Comp Physiol 135:315-325

Stien LH, Fosseidengen JE, Malm ME, Sveier H, Torgersen T, Wright DW, Oppedal F (2014) Low-intensity light of different colours modifies Atlantic salmon depth use. Aquacult Eng 62:42-48

Submitted: August 13, 2014; Accepted: May 27, 2015 Proofs received from author(s): June 29, 2015 